\title{
Proceedings of the meeting of the Association of British Neurologists, in London, 31 October and 1 November 1986
}

\begin{abstract}
A PROGRAM FOR LONG-TERM AMBULATORY CARE IN CHRONIC MULTIPLE SCLEROSIS

HJ Bauer. Department of Neurology, University of Goettingen, West Germany
\end{abstract}

Persons with chronic multiple sclerosis have a life expectancy equivalent to $70-80 \%$ of that of healthy persons. In the majority only $10-20 \%$ of the duration of their illness is spent in hospitals and the far greater portion at home. In most of these cases a continuous, planned programme of ambulatory care is lacking.

The basic idea of the Göttingen programme is to provide, with the help of observation, treatment and education of patients, their families, professional and lay persons to improve the long-term ambulatory care in multiple sclerosis.

During the past five years over 800 patients were seen in the Multiple Sclerosis Information and Counselling Unit of the University of Göttingen. Neurological examinations, checkups, psychosocial counselling and aid measures were carried out and a data bank was established, which now contains the records of 650 multiple sclerosis patients and is able to provide data on numerous features of the disease, single symptoms and their severity (number, names, situation of patients) for special research programmes. The organisation and procedures, initial results and problems encountered will be described.

COMPENSATORY MECHANISMS AT BOTH PRE AND POST SYNAPTIC SITES THAT ACCOMPANY LESION OF CHOLINERGIC CELLS IN RAT BASAL FOREBRAIN

J de Belleroche, IM Gardiner, B Premi, L Reed, F-H Harlow, F Clifford-Rose. Charing Cross \& Westminster Medical School, London

A consistent finding in Alzheimer's disease is the cholinergic deficit in the cerebral cortex. We have investigated the consequences of this deficit on cholinergic properties and post synaptic action in an animal model. Immediately following lesion of the nucleus basalis of Meynert in the substantia innominata of the basal forebrain, cholinergic enzymes and muscarinic receptors are significantly reduced in frontal and parietal cortex. This loss is accompanied by a greatly enhanced response to muscarinic receptor stimulation as measured by the carbachol activation of inositol phosphate production This compensatory effect remains for two months, at which time significant reversal of the cholinergic deficit is seen. This is likely to be due to the "sprouting" of spared axons which occurs at this period. These results indicate that loss of the cholinergic cells in Alzheimer's disease would be accompanied by compensatory processes occurring at both pre and post synaptic sites. Treatment with cholinergic agonists early in the disease would be particularly effective due to the initial enhanced responsiveness but this state would only be maintained for a limited period.

\section{VARIABILITY OF AMPLITUDE IN UNTREATED ESSENTIAL TREMOR}

LCleeves, LJ Findley. MRC NeuroOtology Unit, National Hospital, Queen Square, London, and Regional Centre for Neurology and Neurosurgery, Oldchurch Hospital, Romford, Essex

In addition to a slow progression with age, transient increases in the amplitude of essential tremor can result from a variety of extraneous factors e.g. anxiety, muscular fatigue. It has generally been considered that, in the absence of stress factors, the amplitude of essential tremor does not vary appreciably over short time spans $i e$ weeks/months. We have monitored tremor amplitude in untreated patients with essential tremor in a controlled laboratory situation with the aim of minimising fluctuations due to extraneous factors. In 22 patients postural tremor was recorded accelerometrically, at the same time of day, on 5-12 occasions over a period of 5-20 weeks. In 14 patients tremor was measured hourly for six hours within a single day. Considerable differences in variability of tremor amplitude were found between patients; individual coefficients of variation (standard deviation/mean) ranged from 0.08 to 0.94 (mean 0.43 ) for weekly assessment and 0.09 to 0.87 (mean 0.32 ) for hourly assessment. Regression analysis did not indicate any simple linear relationship between amplitude variability and mean amplitude, mean peak frequency, age, duration of tremor, family history or sub- sequent response to a single oral dose of propranolol. Group means of tremor magnitude for successive hourly measurements were not significantly different. Group means for weekly measurement showed a trend toward lower amplitudes on successive occasions, with mean tremor amplitude on week five significantly lower than that on week one. Time trends are a source of systematic bias in data collections. It is therefore concluded that clinical trials in essential tremor must employ large numbers of patients and rigorous randomisation of treatments in cross-over trials.

ARE HEADACHE CLINICS NECESSARY?

PDavies, FClifford Rose. The Princess Margaret Migraine Clinic

Many neurologists are opposed to specialised headache clinics and the reasons for this are discussed. We hope to show that they have an important role in headache research and in improving treatment.

The Princess Margarent Migraine Clinic at Charing Cross Hospital sees nearly 1,500 new patients each year. An outline of the organisation and facilities of the clinic will be given and a breakdown of the differential diagnosis of headache seen at the clinic will be compared with those attending a general neurology clinic. Information from computer analysis of data will be presented as well as examples from current research projects including SPECT scanning in migraine.

The aims of a headache clinic are:

(a) To produce a large data base on headache syndrome, particularly migraine.

(b) To allow clinicians a wide experience in headache management so that this may be passed on to those less experienced.

(c) To be a referral centre for difficult cases.

(d) To seek out and assess new therapies.

(e) To research into the basic mechanisms of headache production.

DYSPHAGIA IN ACUTE STROKE

CGordon, R Langton Hewer. Stroke Unit, Department of Neurology, Frenchay Hospital, Bristol

A prospective study was undertaken to 
define the incidence, duration and consequences of dysphagia in an unselected group of acute stroke patients; particularly those with hemisphere stroke. There were 91 consecutive patients $(38$ men and 53 women). Dysphagia was defined as the inability to drink $50 \mathrm{ml}$ of water and/or choking more than once whilst attempting to drink $50 \mathrm{ml}$ of water, on at least two occasions. The site of the present lesion and of any previous stroke was determined clinically and was confirmed by CT brain scan or necropsy in 40 cases.

Forty one patients $(45 \%)$ with acute stroke had dysphagia: 37 patients had a hemisphere stroke and four patients had a brainstem stroke. Only seven patients had evidence of bilateral hemisphere lesions. Swallowing recovered within eight days in 16 patients and within six weeks in the remaining six patients who survived their hemisphere stroke.

Patients with hemisphere stroke and dysphagia had more severe strokes on average than those with normal swallowing. There was a higher incidence of transient cranial nerve palsies, dehydration, chest infections and a higher mortality rate. Early detection of dysphagia after stroke may prevent avoidable dehydration and chest infections. Whether or not these measures would influence mortality has yet to be shown.

THE TREATMENT OF CHRONIC RELAPSING INFLAMMATORY POLYNEUROPATHY BY PLASMA EXCHANGE AND IMMUNOSUPPRESSION MLPGross. National Hospital for Nervous Disease, Queen Square, London

Observations are reported on the effects of plasma exchange in 13 patients with chronic relapsing inflammatory polyneuropathy (CRIP). In 12 patients concurrent immunosuppression with prednisolone $(1 \mathrm{mg} / \mathrm{kg})$ plus azathioprine $(2 \cdot 0-2 \cdot 5 \mathrm{mg} / \mathrm{kg})$ was used. Recovery from relapses in these same patients treated by immunosuppression alone was compared with the recovery following plasma exchange and immunosuppression combined. The plasma exchange treated patients had a highly significant $(p<0.005$; Wilcoxon rank sum test) improvement as measured on a functional scale compared with the relapses treated by immunosuppression alone. In seven patients, recovery was noted after the first plasma exchange and in two patients, repeated relapses showed consistent rapid response to courses of plasma exchange therapy.

These findings suggest that plasma exchange combined with immunosuppressive therapy speeds the recovery from relapses in patients with CRIP.

MAJOR HISTOCOMPATIBILITY ANTIGENS AND LYMPHOCYTE SUBSETS DURING EXPERIMENTAL ALLERGIC NEURITIS IN THE LEWIS RAT

RAC Hughes, PF Atkinson, IA Gray, WA Taylor. United Medical and Dental Schools, Guy's Hospital, London

Class I and II Major histocompatibility (MHC) antigens were identified in frozen sections of normal Lewis rat peripheral nerve tissue with monoclonal antibodies and an avidin-biotin-peroxidase complex system. Particularly intense staining for Class I antigen was identified on the endothelium of blood vessels and the arachnoid membrane surrounding nerve roots. Class II antigen was expressed on some endoneurial and perineurial cells in the sciatic nerves. In the cauda equina Class II positive cells were confined to the arachnoid membrane and dorsal root ganglia, but were absent from the endoneurium of the spinal roots. Experimental allergic neuritis was induced in Lewis rats by immunisation with bovine intradural root myelin. Early lesions consisted of multifocal infiltration of the nerve roots by cells expressing leukocyte common antigen. The surrounding endoneurium showed markedly increased expression of MHC Class I and Class II antigen. About $10 \%$ of the infiltrating cells were stained with pan $T$ cell antibodies. The $\mathrm{W} 3 / 25$ positive cells were usually slightly in excess of OX 8 and their relative proportions did not alter during the disease. The presence of MHC Class $I$ antigen on normal endothelium and its markedly increased expression early in EAN suggests an important role in pathogenesis for cytotoxic lymphocytes recognising this antigen.

EFFECT OF TRH ANALOGUE, RX77368, ON SPINAL CORD NEURONS IN CULTURE A Jehanli, R Harrison, GG Lunt, RJ Guiloff.* University of Bath and *Westminster Hospital, London

Engel and colleagues ${ }^{1}$ described improvement in weakness and reduction in spasticity in patients with motorneuron disease (MND) receiving high intravenous doses of TRH. Changes in muscle force, tone, bulbar function and increase in fasciculations in MND patients have also been reported for RX77368, a long acting TRH analogue. ${ }^{2}$ Schmidt-Achert et al $^{3}$ have found that TRH exerts a trophic effect on rat ventral horn neuronal explants, as judged by a 16-for increase in cholineacetyltransferase activit We now report the effects of TRH ang RX77368 on primary cultures of rat spina cord neurons.

Neuron-rich cultures of rat spinal cort cells were established in serum-free medra containing $0 \cdot 1 \mathrm{mM}$ TRH or RX77368. Afte. 10 days, cholineacetyltransferase activity the cultures was found to be increased by $51 \%$ and $55 \%$ respectively, relative to co茞 trols, while binding of monoclonal ant neurofilament antibodies was increased $57 \%$ and $126 \%$ respectively. This demo stration of a TRH-induced trophic effect neurons supports the findings of Schmids Achert $e$ al and, additionally, indicates that RX77368 is more effect in this respect, $\mathrm{a}$ difference that might reflect increas resistance to proteolysis. TRH and RX77368 were shown to bind to the samao

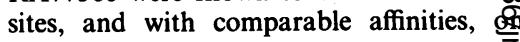
spinal cord membranes.

\section{References}

1 Engel WK, Siddique T, Nicoloff JT. Lanced 1983;ii:73-5.

2 Guiloff RJ, Eckland DJA, Nagendran K, et gI $J$ Neurol 1985;232:(Suppl) 36.

3 Schmidt-Achert KM, Askanas V, Engel Wax $-d$ Neurochem 1984;43:586-9.

THE EARLY EXPERIENCE OF A REHABILITATT WARD WITH AN INTEREST IN NEUROLOGICA DISORDERS

DL McLellan, KJWalsh. Department Rehabilitation, University of Southampto

A review of the activities of the new rehabin itation ward of Southampton General Hog pital is presented. In this time there were 159 admissions. Thirty nine of these were fơ medical investigation only, 31 for asses ment or specific treatment, and 89 for reha bilitation. The 89 rehabilitation admission included 41 men and 48 women. The are range was $15-80 \mathrm{yr}$, mean $49.9 \mathrm{yr}$. Eighty patients were suffering from neurological conditions and nine from arthritis. Forty three patients $(\mathbf{4 8 \%} \%$ were considered have conditions pursuing a deterioratin course, $19(21 \%)$ a static condition and 2 $(30 \%)$ were expected to show some spont? neous improvement.

Patients were admitted either from home or from other hospital wards, and stayed 1-230 days (mean 33.6 days). The initiof assessment included a statement of impairment, disability and handicaP Attempt were made throughout the hospital admission and after discharge to assess the effects of the treatment programme. 
Of 63 rehabilitation admissions eligible to receive a questionnaire after discharge, 42 $(67 \%)$ replied. The great majority found the structure of the ward and the treatment received adequate. Overall, $28(67 \%)$ felt that their condition improved during their stay on the ward and $23(54 \%)$ were continuing to improve after six months. Of those with progressive conditions who replied, seven of $18(38 \%)$ benefitted from their admission and six $(33 \%)$ remained improved at six months.

\section{SUBACUTE COMBINED DEGENERATION}

EH Reynolds. Department of Neurology, Maudsley and Kings College Hospitals, London

Subacute combined degeneration (SCD) used to account for $5 \%$ of neurological admissions, but is now rarely seen by neurologists. Four patients seen over a period of two years are described. One was a 26 year old nurse with pernicious anaemia, equivalent to the youngest case on record. Two middle aged patients had megaloblastic anaemia due to severe folate deficiency, one in association with alcoholism, the other depression. The fourth example had a severe nutritional folate deficiency associated with oesophageal stricture and repeated nitrous oxide anaesthesia for oesophageal dilatation.

Nitrous oxide and cycloleucine models of SCD both suggest that a disturbance in methylation in the spinal cord is responsible for the lesions. Pathological confirmation of SCD in association with an inborn error of folate metabolism has recently been described. The mechanisms underlying SCD in association with vitamin B12 or folate deficiency will be discussed.

\section{SIXTY BRAINS: A CLINICO-PATHOLOGICAL STUDY OF PATIENTS IN GERIATRIC AND PSYCHOGERIATRIC BEDS CL Scholtz, CP Silver. Institute of Pathol- ogy, The London Hospital, London}

The brains of 60 patients (mean age 80.0 years) with neuropsychiatric symptoms, treated in a district where geriatric and psychogeriatric services are unusually closely integrated, were examined in detail. Clinical and pathological features were correlated using a clinical classification, grouping patients according to the predominant clinical feature. Two brains were normal. Atherosclerotic vascular disease with associated loss of brain tissue was the most significant pathological finding in 36 brains $(60 \%)$, nine $(15 \%)$ showed Alzheimer's disease, five (9\%) Parkinson's disease and the remainder diverse pathology. Severe dementia was most commonly due to Alzheimer's disease. Dementia associated with vascular disease was of a lesser degree or accompanied by complex physical disorders and was associated with small vessel disease with associated infarct-like changes in the deep white matter. The clinical grouping presented here allows preliminary assessment of the patient which can be related to underlying pathology.

\section{PARITY AND INCONTINENCE IN MULTIPLE} SCLEROSIS

SJ Snooks, M Swash. Neurology Department, The London Hospital, London and St Mark's Hospital, London

Twelve consecutive patients with multiple sclerosis and incontinence had electrophysiological studies of the pudendal and perineal innervations of the anal and urinary sphincter musculature, and SFEMG fibre density measurements in the external anal sphincter muscle. All the patients had faecal incontinence and eight had urinary incontinence. The fibre density was higher in the parous patients $(1.9)(p<0.001)$ than in the controls $(1 \cdot 5)$ or the non-parous patients $(1 \cdot 7)$. The perineal nerve terminal motor latency was increased in the parous patients and the motor latencies to the periurethral striated sphincter muscle from stimulation at the Ll and L4 vertebral levels were increased, although the spinal latency ratio was normal. The results suggest that incontinence in multiple sclerosis is often due to the interaction of several factors, including central lesions, conus medullaris lesions and, also, coincidental pelvic nerve lesions associated with childbirth. Thus, incontinence is especially a problem in women with the disease.

IMMUNOHISTOCHEMICAL LOCALISATION OF C9 IN MULTIPLE SCLEROSIS

DAS Compston,

BP Morgan, AK Campbell, G Cole, P Wilkins, B Jasani. University of Wales College of Medicine, Cardiff

The time course of onset and recovery from symptoms in multiple sclerosis cannot easily be accounted for by morphological changes seen within plaques; one possibility is that disease activity in multiple sclerosis is due not to demyelination, but another mechanism which can reversibly damage myelin leaving no lasting functional or morphological changes. We have previously reported a reduction in cerebrospinal fluid concentration of the terminal complement component (C9) in patients with multiple sclerosis and isolated demyelinating lesions, irrespective of clinical disease activity. We have now examined fresh frozen brain from three patients with long-standing multiple sclerosis by an immuno-peroxidase method using the same high affinity anti-C9 monoclonal antibody used in our immunoradiometric assay; immunologically specific staining for $\mathrm{C} 9$ was present surrounding blood vessels of all sizes, especially capillaries, and within endothelial cells in all areas of demyelination examined; histologically these were moderately recent plaques. Granular cytoplasmic staining was also present on cells having the morphological and cell surface marker appearances of astrocytes. Neither type of staining was present in unaffected white matter or tissue from 4 patients with other neurological diseases. These results are consistent with the hypothesis that the molecular basis of myelin injury in multiple sclerosis involves the membrane attack complex of complement, not necessarily to the exclusion of other cytopathic processes.

CLONING AND SEQUENCING OF CLASS II MHC GENES IN NARCOLEPSY

CB Lock, AKL So, KI Welsh, JD Parkes Tissue Typing, Guy's Hospital; Imperial Cancer Research Fund; Department of Neurology, King's College Hospital

Narcolepsy is unique amongst sleep disorders in having a strong HLA Class II association at the protein level with the antigens DR2 and DQwl. The findings have been extended to the DNA level, firstly by restriction fragment length polymorphism (RFLP) studies, and secondly by cloning. RFLP data confirm the DR2 association, and the connection with DR2 Dw2. In nonCaucasoid narcoleptics who are DR2 negative, narcolepsy is still associated with a particular DQ gene RFLP. It seems likely that the MHC association in narcolepsy is with a Class II gene and not with a linked gene. We have therefore made EBV transformed cell lines from a narcoleptic subject, and from a subject with an unrelated but strongly DR2-associated disease (Goodpasture's syndrome). We have constructed a cDNA library, screened for Class II alpha and beta chain genes, and obtained sequence data Results will be compared with those from clinically normal DR2 positive subjects. 
Narcolepsy may be associated with specific nucleotide sequence alterations in Class II genes.

MAGNETIC STIMULATION OF THE HUMAN BRAIN

AT Barker, ${ }^{*} \quad$ IL Freeston, + , $\quad$ R Jalinous, ${ }^{*}$ JA.Jarratt. $\dagger$ Department of Medical Physics and Clinical Engineering, * Department of Clinical Neurophysiology, Royal Hallamshire Hospital, $\uparrow$ Sheffield, Department of Electronic and Electrical Engineering, University of Sheffield $\ddagger$

A new and painless method of stimulating the unexposed human brain by means of a pulsed magnetic field was described by Barker, Jalinous and Freeston in $1985 .^{1}$ The technique also enables deep peripheral nerves to be stimulated. This paper presents the findings in 27 control subjects, 15 patients with multiple sclerosis, five patients with motor neurone disease and nine patients with Parkinsonism. Conduction in motor pathways was slowed in the patients with multiple sclerosis but not in the other groups. In general, the slowing was more marked in the chairbound than in the mobile patients.

We have also found slowed conduction in another group of patients with multiple sclerosis who had normal visual evoked potentials.

As might be expected, slowed conduction is not exclusive to multiple sclerosis; examples have been found amongst patients with cervical spondylosis.

The technique promises to be useful in the diagnosis of disorders of central motor pathways and inaccessible portions of peripheral nerves, and may help to evaluate treatment regimes.

\section{Reference}

I Barker AT, Jalinous R, Freeston IL. Lancet 1985;:1106-7.

SOME CLINICAL ASPECTS OF CENTRAL MOTOR CONDUCTION

CW Hess, KR Mills, NMF Murray. National Hospital, Queen Square, London

Central motor conduction (CMC) was studied in 21 controls and 43 patients with neurological disease. Responses were recorded from abductor digiti minimi (ADM) to magnetic brain stimulation and electrical stimulation over the $\mathrm{C} 7 / \mathrm{T} 1$ interspace: the latency difference is a measure of CMC time. Abnormality was defined as (1) CMC time greater than $8.0 \mathrm{~ms}$ ( $>$ mean $+2.5 \mathrm{SD}),(2)$ reduced amplitude on cortical stimulation ( < mean $-2.5 \mathrm{SD}$, amplitude expressed as percentage of response on wrist stimulation) or (3) no response to brain stimulation.

CMC was abnormal in $85 \%$ of 15 patients with definite multiple sclerosis and subclinical motor abnormalities were demonstrable in $10 \%$ of definite or suspected multiple sclerosis cases; responses were small and often very prolonged. In disorders such as MND, with neuronal degeneration rather than demyelination as the primary process responses tended to be reduced but only slightly delayed.

The best clinical correlate of pathological $\mathrm{CMC}$ was hyperreflexia of the tested limb. CMC was abnormal in two-thirds of arms with hyperreflexia and tendon jerks were exaggerated in $82 \%$ of arms with abnormal CMC. In contrast fine finger movements were impaired on $46 \%$ of sides with pathological CMC and ADM was weak in only $36 \%$.

The procedure is rapid, well-tolerated, and aids clinical evaluation of motor pathways.

ABNORMALITIES OF CENTRAL MOTOR CONDUCTION IN MULTIPLE SCLEROSIS REVEALED BY TRANSCUTANEOUS MAGNETIC STIMULATION OF THE BRAIN

DA Ingram, AJ Thompson, M Swash. The London Hospital, London

Effective stimulation of central motor tracts in man can now be achieved using transcutaneous magnetic stimulation of the brain. ${ }^{1}$ We have used this technique to study motor conduction in the brain and spinal cord of 20 patients with clinically definite multiple sclerosis. Stimulation was carried out over the cortex, cervical spine and lumbar spine whilst simultaneous surface recordings were made from biceps brachii (BB), thenar eminence and tibialis anterior (TA) muscles bilaterally. Subtraction of the latency following spinal stimulation from that following cortical stimulation gave a measure of central motor conduction time (CMCT) for each muscle. Weak background facilitation was used to obtain the shortest latency during cortical stimulation. The results were compared with control values obtained from 10 healthy volunteers aged between 24 and 53 years; normal mean CMCT values $( \pm$ SD) were $6.3 \pm 1.1 \mathrm{~ms}$, $7.6 \pm 0.8 \mathrm{~ms}$, and $15.0 \pm 1.5 \mathrm{~ms}$ for $\mathrm{BB}$, thenar eminence and TA muscles respectively.

In multiple sclerosis patients, markedly prolonged CMCTs, up to three times no\& mal, were often found. These correlated with signs of upper motor neuron dise turbance. CMCTs for lower limb muscle were directly related to functional motoo disability (Kurtzske and Ambulatory Inde scales). Evidence of subclinical involveme of central motor tracts was also present $\overline{\mathbf{m}}$ some subjects. This new technique is virt度 ally painless and will prove valuable in the diagnosis and monitoring of patients with multiple sclerosis.

\section{Reference}

1 Barker AT, Jalinous R, Freeston IL. Lanc 1985;:11106-7.

VERGENCE EYE MOVEMENT CONTROL IN NORMAL AND DYSLEXIC CHILDREN JF Stein, PM Riddell, MS Fowler. Unive sity Laboratory of Physiology, Oxford

Many developmental dyslexics are referreg to eye departments because they complain that they cannot see properly: they lose theip places on a page; letters and words seem to swim around and change their order. On examination their eyes are usually found to be normal. By measuring these childrens' eye movements, however, we have sh@̂f that two-thirds of dyslexics exhibit inate rate vergence responses to small fusion $s$ uli such as letters. Poor vergence con Frợ causes them to mislocalise small object? hence their "visual" problems with readine Probably it is also the explanation for the lowered stereoacuity. We have shown tha most good readers have accurate vergence control, so they do not mislocalise small tå gets. Monocular occlusion may assist abouf half of dyslexics with poor vergence contro to improve it; thereafter many of these chif dren catch up with their reading. Thus diso dered fine vergence control may be ar important cause of childrens' reading difficulties, and improving the vergence corous trol of development dyslexics may help thein to improve their reading.

SYRINGOMYELIA: COMPARISON OF SYMPTOMS AND SIGNS WITH CYST MEASUREMENT BY MAGNETIC RESONANCE IMAGING

R Grant, DM Hadley, PMacphersom. B Condon, I Bone, GM Teasdale. Institute of Neurological Sciences, Glasgow

The distribution and severity of symptomss and signs in patients with syringomyelig have been considered to be dependent upor the longitudinal and transverse dimensiof

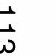


of the syrinx. Magnetic resonance imaging (MRI) has made the localisation and assessment of the extent of cystic intramedullary spinal lesions more sensitive and specific.

Full clinical examination was carried out within two weeks of MRI, on 12 consecutive patients with untreated syringomyelia, unassociated with spinal cord tumour. Using a Picker Vista $1100 \quad 0.15 \mathrm{~T}$ resistive magnetic operating at $6.38 \mathrm{MHz}, \mathrm{T}_{1}$ weighted $8 \mathrm{~mm}$ contiguous sagittal and selected axial slices were obtained of the head and spine, using a standard head coil and purpose built spinal surface coils. Cyst site, length, diameter, cyst:cord and cord:canal ratios were measured with electronic calipers after enlarging the area of interest $\times 4$ on the viewing console. Measurements were reported independently, without access to clinical information.

No significant relationship was found between the anatomy of the cyst and the presence of wasting, weakness, distribution of sensory loss or degree of stability. This should be borne in mind when the supposed severity of syringomyelia is being assessed and when operative intervention is being considered.

ATTEMPTS TO IMPROVE SENSORY ATAXIA WITH EXTEROCEPTIVE CUES

CD Ward. University of Southampton Department of Rehabilitation, Southampton General Hospital

Two patients with peripheral neuropathy, two with cervical spondylosis, and one with a cervical cord lesion of uncertain nature, all had disabling proprioceptive loss with relative preservation of skin sensation. Attempts were therefore made to induce skin sensation during joint movements as a means of restoring position sense. Using various simple methods improvement was equivocal in one patient, definite but not functionally useful in a second, and definitely beneficial in a third; the remaining two did not improve. The patient with most marked benefit had independently discovered that the use of gloves was helpful: they increased correct response rate on routine joint position sense testing from $80 \%$ to $100 \%$. Gloves also increased the maximum rate of finger movement in a simple test of dexterity from 1.8 to 2.3 movements/s (eyes open), and from 0.9 to 2.8 movements/s (eyes closed). It is concluded that residual skin sensation can be used to lessen disability caused by proprioceptive 'impairment. Results will be illustrated with video recordings.
MRI BRAIN SCANNING IN PATIENTS WITH SYSTEMIC VASCULITIS: POSSIBLE CONFUSION WITH MULTIPLE SCLEROSIS

DAS Miller (Introduced), IEC Ormerod (Introduced), P Rudge, WI McDonald. Institute of Neurology, Queen Square, London

MRI scanning is sensitive in the detection of brain lesions in patients with multiple sclerosis and cerebral vascular disease. We have previously reported the similarity of scan appearances in these two conditions, but many with cerebral vascular disease were in an older age group, where MRI changes are frequent in the normal population. We therefore examined 23 patients aged 14 to 62 years (mean 36 years) with vasculitis, including nine with Behcets disease and nine with SLE.

Fifteen had abnormal brain scans: periventricular changes (in 11 patients), discrete hemisphere lesions (nine), infarction in the territory of a major cerebral vessel (two), brain stem lesions (one), and cerebral lesions (one). Eleven of 15 with clinical CNS involvement had an abnormal brain scan. Four of eight without CNS features had abnormal scans.

Eight had multiple periventricular lesions resembling those seen in multiple sclerosis although they were general less extensive. Clinically silent lesions were found in 11 . Three had both CT and MRI scans. In each case CT was normal, and MRI abnormal.

MRI is sensitive in detecting both silent and clinically expressed brain lesions in patients with vasculitis. The pattern of abnormality sometimes permits a distinction to be made between multiple sclerosis and vasculitis.

CLINICAL AND PATHOLOGICAL FEATURES OF INTRACRANIAL TUMOURS IN THE DOG

AC Palmer (Introduced). Department of Clinical Veterinary Medicine, Madingley Road, Cambridge

A survey was carried out on 21 cases on naturally-occurring tumours of the brain in dogs with particular reference to the correlation of clinical manifestations with the neuroanatomical localisation of the lesion. Apart from signs related directly to focal damage of the brain, others could be ascribed to secondary effects caused by herniation of the cingulate gyrus, coning of the cerebellum, to haemorrhage, ischaemia and to spread of tumour, possibly by way of the CSF. Many gliomas arise from the area of the subependymal plate and this appears to determine the pattern of subsequent clinical events as well as the frequency of their occurrence. The most common clinical features were change of temperament, locomotor abnormalities, visual defects (including hemianopia) and fits; the least common were brain stem signs. Ten out of the 21 cases occurred in the Boxer dog, suggesting a breed predisposition. The difficulties of diagnosis and differential diagnosis will be described.

THE NEUROLOGICAL COMPLICATIONS OF LYME DISEASE IN HAMPSHIRE

DE Bateman, JE White, ${ }^{*}$ RJ Greenwood, $\dagger$ NF Lawton. Wessex Neurological Centre, Department of Dermatology, Southampton General Hospital, * Department of Neurological Sciences, St Bartholomew's Hospital, $\uparrow$ London

Lyme disease was first recognised in America in 1976. The causal agent has been identified as a spirochaete, Borrelia burgdorferi which is transmitted by the bite of a hard tick usually hosted by deer. Lyme disease begins with a unique skin disorder, erythema chronicum migrans (ECM), followed in a proportion of patients by neurological, cardiac and arthritic complications. Although ECM has occurred in England and Scotland only a single patient with neurological disease has been reported. ${ }^{1}$

We now report neurological complications in three further patients with Lyme disease, all of whom probably contracted the disease in the New Forest area of Hampshire. One patient, a man aged $23 \mathrm{yr}$, presented with bilateral facial palsy following ECM. The CSF abnormalities were a total protein of $3.2 \mathrm{~g} / \mathrm{l}$ and 28 lymphocytes per $\mathrm{mm} .^{3}$ Complete recovery followed treatment with parenteral penicillin and oral tetracycline. A second patient, a male aged $42 \mathrm{yr}$, also presented with bilateral facial palsy and radicular symptoms. The CSF showed 498 lymphocytes and a protein of $1.48 \mathrm{~g} / \mathrm{l}$. Recovery followed a course of oral penicillin. The third patient, a girl aged $13 \mathrm{yr}$, was of particular interest. Her neurological illness relapsed on two occasions in spite of high dose parenteral penicillin given during the first relapse. She initially presented with meningo-encephalitis and cerebellar signs but in subsequent relapses showed signs of transverse myelitis. The CSF showed characteristic cellular and protein abnormalities with the addition of oligoclonal bands in the first attack only. The diagnosis in each case was confirmed by raised serum titres to Borrelia burgdorferi. 
The fact that these cases all occurred within a short time of one another suggests that the neurological complications of Lyme disease may be more common than previously supposed. Whether a single course of penicillin results in cure remains in doubt.

\section{Reference}

1 Williams D, Rolles CJ, White JE. Lyme Disease in a Hampshire child: medical curiosity or beginning of an epidemic. $\mathrm{Br}$ Med $J$ 1986;292:1560-1.

\section{A POPULATION-BASED STUDY OF PERIPHERAL} NEUROFIBROMATOSIS

SM Huson, PS Harper, DAS Compston. University of Wales College of Medicine, Cardiff

A population-based study in South Glamorgan and West Gwent (population 667,900 ) identified 136 patients with peripheral neurofibromatosis (prevalence $20 / 10^{5}$ ). In addition to multiple café au lait spots, or cutaneous neurofibromas, freckling was present in the axilla $(69 \%)$ groin $(37 \%)$ or sub-mammary areas $(33 \%$ of adult females). Although not a criterion for diagnosis, Lisch nodules were invariably present in the iris $(96 \%$ of patients overall: $100 \%$ of adult cases). Plexiform neurofibromas, often appearing in childhood, complicated $30 \%$ of cases. Other associated neurological conditions included epilepsy (seven) aqueduct stenosis (two) spinal neurofibroma (two) optic nerve glioma (one) and meningioangiomatosis (one); there were no cases of acoustic neuroma. Patients with isolated neurofibromas (one) plexiform neurofibroma (one) spinal Schwannoma (one) or bilateral acoustic neuroma (one) were excluded. Non-neurological disorders, some known to be associated with neurofibromatosis, identified in the index cases consisted of scoliosis (11) pseudoarthrosis of the tibia and fibula (four) gastrointestinal neurofibroma (three) renal artery stenosis (two) delayed puberty (two) carcinomas (two) duodenal carcinoid (two) phaeochromocytoma (one) congenital glaucoma (one) cardiomyopathy (one) and congenital heart disease (one). Six affected relatives had died from malignant disease; considering all living family members aged more than 18 years, together with their deceased relatives, the incidence of malignancy related to neurofibromatosis was approximately $6 \%$.

Uncomplicated, neurofibromatosis is disfiguring but not a major cause of morbidity; the management of the disease relates to its complications which can be categorised as benign, occurring in childhood (plexiform neurofibromas, orthopaedic and mental retardation: 19\%) or at any time (benign central nervous system disorders, visceral and renal complications: $15 \%$ ), and malignant (central nervous system and visceral tumours: $6 \%$ ).

\section{THE LATE SEQUELAE OF POLIOMYELITIS}

RS Howard, GT Spencer, CM Wiles, The respiratory Unit and Department of Neurology, St. Thomas' Hospital, London.

Progressive functional deterioration following acute poliomyelitis can occur after a prolonged period of stability. We present follow up data on 208 patients; the period from the original illness to December 1985 or death was between two and 73 years (mean 33.8 years).

One hundred and sixty-two (77.9\%) patients developed late functional deterioration. This was due to purely respiratory factors in 99 cases, new neurological signs in 19 cases, and orthopaedic problems in 17 cases; 27 patients deteriorated due to a combination of factors. The commonest cause of respiratory deterioration was the development of alveolar hypoventilation in association with progressive scoliosis. Eighty-five patients needed respiratory support commencing between one and 66 years (mean 28.2 years) after the acute illness. New neurological signs were due to a clearly defined cause in each of the 19 patients. No cases of motor neurone disease or post-polio muscular atrophy were identified. This study shows that late sequelae following poliomyelitis are common. The major causes of functional deterioration may be treatable or even avoidable.

AMNESTIC STROKE: A NEUROPSYCHOLOGICAL STUDY

JR Hodges. University Department of Clinical Neurology, Radcliffe Infirmary, Oxford

Amnestic stroke is probably more common than is recognised as it usually masquerades as dementia without the classic features of stroke. Although a number of such cases have now been reported, remote memory has not been examined in detail and no attempt has been made to correlate anterograde and retrograde amnesia with lesion site. The study of these non-alcohola Korsakoff's cases may shed light on sorfe controversies surrounding the amnestic syndrome.

Six patients (four men and two women aged 41 to 65 years) with severe, selective, amnesia secondary to discrete deep strokes have undergone an extensive battery neuropsychological tests designed investigate anterograde and retrograde memory. Two have bilateral thalam蒫 infarction, one a left thalamic infarct, one a left thalamic haemorrhage and two left posterior medial temporal infarcts.

All have a profound verbal learnim deficit, but, those with left thalamic lesio have relatively preserved non-verbal memory. Remote memory was investigated by structured autobiographical interview, $\bar{a}$ cued personal memory (Crovitz) test, famous faces and famous events tests. The extent of retrograde amnesia varies between cases from a few years to many decades a in general correlates with the severity of the anterograde amnesia and the lesion sice There is also good evidence of a temporal gradient with sparing of more distan memories.

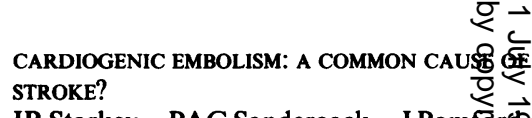
IR Starkey, PAG Sandercock, J Bamgir CP Warlow. Department of Clinical Neचr logy, Radcliffe Infirmary, Oxford

A case-control study has been used to con pare the prevalence of cardiac disease in tu groups of patients with cerebral infarction consecutive series of hospitalised patien and a consecutive series of patients referrest to the Oxfordshire Community Strof Project) with that in a group of age- and sexmatched control subjects.

One or more "probable sources of embolism" (eg rheumatic mitral stenos, recent myocardial infarction, infective endo carditis, etc) was present in 41/198 patients with cerebral infarction $(20.7 \%)$, but on $7 / 198$ controls $(3.5 \%)\left(\chi^{2}=27.4 ; p\right.$; $0.001)$. An additional 70 patients (35.4\% had one or more "possible sources of embolism" (eg mitral annulus calcificatio¥, old myocardial infarction, etc) as did control subjects $(30 \cdot 3 \%)$. Eighty-seven patients $(43.9 \%)$ and 131 controls $(66.2 \%$ had no source of embolism found.

From these figures, it seems likely thaf many cardiac lesions reported previously as being "possible sources of embolism" a a unlikely to be directly responsible for cere bral infartion. Embolism from the heart 
the brain is likely to have been the cause of cerebral infarction in no more than about $20 \%$ of our patients.

\section{CLINICAL FEATURES OF BORDER ZONE} ISCHAEMIA

RW Ross Russell. The National Hospital for Nervous Diseases, Queen Square, London

Cerebral arterial border zones were first shown by injection studies. They traverse all lobes of the hemisphere and a border zone common to all three main arteries exists in the parieto-occipital region. Ischaemic lesions confined to these regions occur following episodes of systemic hypotension or after cardiac surgery. Extracranial artery occlusion predisposes to border zone infarction and influences the distribution of the lesion. The symptomatology of border zone ischaemia can be divided into three groups:

(1) Common border zone (bilateral parietooccipital) lesions produce the syndrome of visual disorientation with defective visual judgement of size, distance and motion and with visual inattention. There is a variable amount of cortical blindness worse in the lower fields. Abnormalities of smooth pursuit eye movements also occur.

(2) Bilateral lesions in the anterior-middle border zone involve posterior frontal and parietal lobes and produce bibrachial weakness and cortical sensory loss most marked in the hands. There is also temporary paralysis of voluntary conjugate gaze.

(3) Bilateral lesions in the middle-posterior border zones produce dyslexia, dyscalculia and constructional dysparxia with memory loss both for verbal and non-verbal material.

These clinical features are illustrated with reference to nine patients suffering varying degrees of brain damage-after cardiac surgery (five patients), pulmonary embolism (two patients), haemorrhagic or postoperative hypotension (two patients).

HAEMOGLOBIN CONCENTRATION AND PROGNOSIS IN SYMPTOMATIC OBSTRUCTIVE CEREBRO-VASCULAR DISEASE JPH Wade, DW Taylor, HJM Barnett, VC Hachinski. University Hospital, London, Ontario

Patients with polycythaemia suffer a high incidence of stroke and an elevated $\mathrm{Hb}$ concentration appears to be a risk factor for stroke in the normal population. Data from retrospective studies suggest that the severity of carotid disease and the level of the $\mathrm{Hb}$ concentration act synergistically. We have examined this relationship in a prospective study.

A total of 1,377 patients with symptomatic obstructive cerebrovascular disease (most commonly internal carotid artery occlusion) entered a trial in which they were randomised to either medical or surgical therapy (EC/IC Bypass). All but eight had haemoglobin estimations performed at entry. The patients were followed for an average of 55.8 months. In the medical group, the 325 patients with high normal haemoglobin concentration ( $15 \mathrm{~g} / 1$ or more) suffered no more ischaemic strokes than the 382 patients with lower values (below $15 \mathrm{~g} / \mathrm{l}$ ). These strokes which did occur were no more severe in the high than the low Hb group. Haemoglobin concentration did not emerge as a prognostic factor in those patients treated surgically $(n=662)$.

This prospective study counters the hypothesis that high normal $\mathrm{Hb}$ concentration is associated with poor outcome in patients with symptomatic obstructive disease of the carotid and cerebral arteries.

ANTI-ACETYLCHOLINE RECEPTOR ANTIBODIES AND THE ROLE OF THE THYMUS IN

MYASTHENIA GRAVIS

F Heidenreich, M Schluep, A Vincent, HNA Willcox, J Newsom-Davis. Department of Neurological Science, Royal Free Hospital School of Medicine, London

Antibodies to the acetylcholine receptors (AChRs) of striated muscle are the main cause of weakness in myasthenia gravis (MG). The thymus, which contains rare muscle-like myoid cells, is often abnormal but its aetiological role is not clear. We have used a panel of mouse monoclonal antibodies raised against human $\mathrm{AChR}$ to define, in a competition assay, serum antiAChR specificities in 65 patients, to compare specificities of anti-AChR antibodies made by cultured MG thymic cells, and to look for thymic AChR.

Anti-AChR specificities differed significantly between the three main patient subgroups defined by thymic pathology and age at onset. Serum anti-AChR specificities had not changed significantly at one year after thymectomy, although total antiAChrR levels often declined $(n=24)$. Myoid cells consistently stained positively for AChR in control $(n=8)$ and myasthenic ( $n=47$ ) thymus, but did not appeär to be the focus of an immune reaction.
The specificities of anti-AChR synthesised by cultured thymic cells closely parallelled those in autologous serum, implying that the thymus contains a representative sample of the cell population generating anti-AChR. Whether myoid cell AChR is involved in triggering or sustaining the autoimmune response in MG remains to be determined.

PERIPHERAL NEUROPATHY COMPLICATING CASTLEMAN'S DISEASE

M Donaghy, PHall, S Liebowitz,* RHM King, $\dagger$ PK Thomas. $\dagger$ St Bartholomew's Hospital London, Guy's Hospital Medical School London,* Royal Free Hospital School of Medicine London $\dagger$

Four patients aged 24 to 55 years with Castleman's disease (angiofollicular lymph node hyperplasia) developed peripheral neuropathy. Severe generalised limb weakness progressively developed over months, accompanied by areflexia and mild distal sensory loss. Three patients had papilloedema, three had ischaemic heart disease or peripheral vascular disease, and two had gynaecomastia. Electromyography revealed widespread denervation with relative preservation of motor nerve conduction velocities. Spinal fluid protein was elevated (1.5 to $2 \cdot 2 \mathrm{~g} / \mathrm{l})$ and the porphyrin excretion, blood sugar and blood lead were normal. Sera from all four patients were tested in antibody activity to human peripheral nerve antigens, including myelin associated glycoprotein, with negative results. Sural nerve biopsy showed active axonal degeneration accompanied by macrophage infiltration. The endoneurial blood vessels were hyperplastic with thickened walls and increased numbers of hypertrophied endothelial cells and pericytes. The epineurium contained excessive numbers of small blood vessels, but there was no evidence of inflammatory vasculitis. These findings suggest that ischaemia causes peripheral neuropathy in Castleman's disease and it arises on a multifocal microvascular basis. One patient was treated with cyclophosphamide and prednisolone and his strength improved substantially after a latency of six months.

PERIPHERAL NER VE DYSFUNCTION IN MILLER FISHER SYNDROME: EVIDENCE FROM SERIAL, MULTIMODAL CONVENTIONAL AND RECENTLY INTRODUCED NEUROPHYSIOLOGICAL

TECHNIQUES

GA Jamal,* JP Ballantyne. $†$ Department of Neurological Sciences, St Bartholomew's Hospital,* London, Institute of Neurological Sciences, $\dagger$ Glasgow 
There has been a continuing debate as to whether the syndrome of acute ophthalmoplegia, ataxia and areflexia (Fisher syndrome) is related to acute inflammatory polyneuropathy, ${ }^{12}$ or is due to a brainstem encephlitis. ${ }^{3-5}$ In this study the results of serial comprehensive neurophysiological tests from onset till and after full recovery in three patients with classical presentation are reported. These included EMG and nerve conduction studies, late response $(\mathrm{H}$ and $\mathrm{F}$ wave) studies, facial nerve and blink reflex studies, motor unit number estimation and motor unit potential analysis, computerised quantitative sensory threshold measurements, ${ }^{6}$ quantitative pupillometric and pupillo-pharmacological studies and multimodality evoked potential (VEP, SSEP and BSAEP) studies.

The results provided unequivocal evidence of peripheral nerve dysfunction and improvement of the neurophysiological parameters accompanied or followed clinical recovery in all the patients. No abnormality in the CNS pathways was found. The findings support the notion that this syndrome is to be included within the spectrum of acute inflammatory polyneuropathy.

We recommend that, when in doubt, detailed neurophysiological studies are useful for differentiation of this benign syndrome from more serious pathologies and that serial measurements are of value in detecting milder peripheral nerve lesions.

\section{References}

1 Fisher M. N Engl J Med 1956;255:57-65.

2 Ropper AH (Editorial). Arch Neurol 1983;40:397-8.

3 Bickerstaff ER. Br Med J 1957;1:1384-7.

4 Al-Din AN, et al. Brain 1982;105:481-95.

5 Meienberg O, Ryffel E. Arch Neurol 1983;40:402-5.

6 Jamal GA, et al. J Neurol Neurosurg Psychiatry 1985;48:354-60.

STUDIES OF RESPIRATION DURING SLEEP IN MYOTONIC DYSTROPHY AND OTHER NEUROMUSCULAR DISEASES

TJ Walls, BG Cooper, JJ Gilmartin, GJ Gibson, CG Griffiths, PHudgson, JW Osselton, TN Stone, D Veale. Muscular Dystrophy Research Laboratories, Newcastle General Hospital and Department of Respiratory Medicine, Freeman Hospital, Newcastle upon Tyne

Disordered central ventilatory control has been postulated in myotonic dystrophy, but is unproven. Indeed the usual indices of ventilatory control are reduced in any subject with respiratory muscle weakness rendering direct methods of assessment invalid. To try to circumvent these problems we have studied breathing during sleep in 21 subjects (seven normal controls, seven with myotonic dystrophy and seven with other neuromuscular disease with similar degree of weakness of their respiratory muscles). The patients in the myotonic dystrophy group had significantly more apnoeas than the controls $(\mathrm{p}<0.01)$, while the frequency in the non-myotonic patients was similar to the controls. Apnoeas occurred in all sleep stages and were predominantly central although in one myotonic subject, obstructive apnoeas also occurred. Mean nocturnal $\mathrm{SaO}_{2}$ was significantly reduced in the myotonic group compared with the controls $(p<0.01)$ and they spent on average $12 \cdot 8 \%$ of their sleep with an $\mathrm{SaO}_{2}$ $<90 \%$ compared with no desaturation below $90 \%$ in controls ( $\mathrm{p}<0.01$ ). Mean $\mathrm{SaO}_{2}$ was not significantly reduced in the non-myotonic subjects and they spent on average $0.9 \%$ of their sleep with $\mathrm{SaO}_{2}<$ $90 \%$ ( $p<0.05$ compared with normal). Sleep apnoea is common in mytonic dystrophy, is not simply due to respiratory muscle weakness and may be related to abnormal central ventilatory control.

PROGNOSIS OF GUILLAIN-BARRÉ SYNDROME J Winer, RAC Hughes. United Medical and Dental Schools, Guy's Hospital, London

One hundred cases of acute idiopathic neuropathy were studied prospectively to identify features influencing prognosis. After one year $67 \%$ had made a satisfactory recovery, $20 \%$ were incapable of manual work and $13 \%$ had died. Significant residual disability was not seen in patients who remained capable of walking and was rare in those who retained some tendon reflexes. It was more common after a rapid onset, in older patients, if ventilation had been required, and in women.

Serological evidence of infection with Campylobacter jejuni but not cytomegalovirus was significantly associated with lasting disability.

Electrophysiological features of poor outcome included absent distal evoked muscle action potentials and markedly slowed upper limb motor nerve conduction velocity.

Severe paralysis was slightly more frequent in patients with the HLA specificity DR 2 but no association of severity or outcome was seen with antibodies against nerve antigens, immune complexes, complement concentrations (C3 and C4) or lymphocyte subsets.
Clinical features and motor nerqe conduction were combined in a modil developed with a computer packace (Generalised Linear Interactive Modellin) and predicted outcome correctly in $84 \%$ of patients.

EMISSION TOMOGRAPHY IN THE DIFFERENTIA DIAGNOSIS OF DEMENTIA D Neary, NMacDermott, JS Snowd $\overrightarrow{\text { A }^{1}}$, B Northen, RA Shields, AWI Burjañ, MC Prescott, HJ Testa. Department of Nemrology, Manchester Royal Infirmary, M每 chester

The diagnostic capability of single photon emission tomographic (SPET) imaging of the brain using ${ }^{99 m}$ TC-hexamethyl propylene amine oxime (HM-PAO) was evatuated in patients with different forms $\mathrm{g} f$ cerebral atrophy.

Imaging was carried out in 38 patien diagnosed on the basis of neurological and neuropsychological examination as suffering from (a) Alzheimer's disease (21), (t) non-Alzheimer dementia of frontal-lớ type (9) or (c) progressive supranuclear palsy (8). In a minority of cases the diagissis was confirmed by cerebral biopsy. Images, examined without knowledge cof clinical diagnosis, were classified as shoming normal grey/white matter uptake ondisplaying reduced uptake in the anceroor and/or posterior cerebral hemispheres?

Posterior hemisphere reductions Th

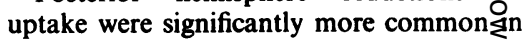
patients with Alzheimer's disease than other patients, and corresponded with the presence of visuo-spatial deficits detected 윰 psychological examination. Selective anferior hemisphere reductions in uptake ch $\overrightarrow{\not{B}}$ acterised both non-Alzheimer demenfia groups: dementia of frontal type a $\overline{7}$ d progressive supranuclear palsy. The pattecinn of anterior hemisphere abnormality was identical in these two groups permitti their differentiation on the basis of the tomographic images.

It is concluded that the imaging technique has potential value in the differential diegnosis of dementia due to cerebral atroph

$\begin{array}{ll}\text { AN EVALUATION OF HIGH-DOSE CONTRAST } & \text { 을 } \\ \text { DELAYED CT-SCANNING IN MULTIPLE } & \frac{2}{2} \\ \text { SCLEROSIS } & \text { 늘. }\end{array}$
GDS Wright, P Anslow, CJF Davis. The Department of Neurology, The Radclife Infirmary, Oxford

Characteristic changes may be found in CT scans of patients with multiple sclerơ⿱宀:s. 
Unenhanced scans may show atrophy and white matter low density lesions. Contrast enhanced scans may show additional enhancing lesions and the yield of these is increased by using high doses of contrast and by delaying the scan.

High-dose contrast delayed CT scanning has been used in Oxford in the investigation of suspected multiple sclerosis for the last two years. The patients are given contrast by bolus plus infusion or infusion alone in doses of up to $75 \mathrm{~g}$ of elemental iodine and are scanned on a Siemens DR1 Scanner after one hour's delay.

The results of this investigation in 100 consecutive patients, in whom the diagnosis of multiple sclerosis was suspected, have been examined. The patients have been clinically classified using the criteria outlined by Poser et al. ${ }^{1}$ Enhancing and/or low density lesions were found in $68 \%$ of the 22 patients with clinically definite multiple sclerosis, in $72 \%$ of the 25 patients with clinically probable multiple sclerosis and in $45 \%$ of those patients in whom the diagnosis of multiple sclerosis was only possible.

Ninety-two patients had visual evoked responses examined and 84 patients had their CSF examined for either oligoclonal banding or the IgG/albumin ratio. The results from these investigations increased the yield of diagnoses of definite or probable multiple sclerosis. The results from scanning, by indicating the presence of anatomically discreet lesions, enabled us to make a diagnosis of probable multiple sclerosis in six additional patients and a diagnosis of definite multiple sclerosis in five additional patients.

High dose delayed contrast CT-scanning increases one's ability to diagnose multiple sclerosis even after the results of visual evoked responses and CSF examination have been taken into account. We find this a useful, readily available and economical investigation in the assessment of patients with suspected multiple sclerosis.

\section{Reference}

1 Poser CM, Paty DW, Scheinberg L, et al. New diagnostic criteria for multiple sclerosis: guidelines for research protocols. Ann Neurol 1983;13:277-331.

AN ASSESSMENT OF THE ROLE OF GADOLINIUMDTPA IN MAGNETIC RESONANCE IMAGING OF INTRACRANIAL MASSES

JPStack, RA Metcalfe, I Isherwood. Departments of Diagnostic Radiology and Neurology, University of Manchester

This prospective study was designed to assess the role of the paramagnetic contrast agent Gadolinium-DTPA in Magnetic Resonance Imaging (MRI) of intracranial masses. Forty-five patients with a variety of intracranial lesions demonstrated by CT were examined with MRI pre- and postGadolinium-DTPA $(0.1 \mathrm{mmol} / \mathrm{kg})$ injection on a Picker International superconducting magnet operating at 0.26 Tesla. A variety of Spin Echo sequences were used.
Pre-contrast T2-weighted Spin Echo sequences (TE 60-80, TR 1500-2000) were found to be the most sensitive in detecting intracerebral lesions, although in general they failed to discriminate pathological tissues. Post-contrast T2-weighted images did not yield any additional information. T1-weighted Spino Echo sequences (TE26, TR 500-700) demonstrated tumour enhancement in 12 out of 18 gliomas, effectively separating tumour mass from oedema. All patients with meningiomas (three), acoustic neuromas (three), neurofibromas (two), metastases (four) and colloid cysts (two) demonstrated tumour enhancement. Five mature cerebral infarcts did not enhance, nor did the vascular lesions (AVM 2, gloma jugulare 2). The post-Gadolinium scans directly altered diagnosis and management in six patients.

In an attempt to characterise pathological tissue, post-Gadolinium signal intensity time profile studies over a period of 50 minutes using a Tl-weighted Spin Echo sequence were employed in nine patients.

We feel that Gadolinium enhanced MRI is likely to be useful in a number of areas. These include: (1) Reduction of scan time. (2) Monitoring disease activity. Screening for acoustic neuromas. (4) Differentiation of tumour from oedema in $\bigcirc$ high grade gliomas. (5) The detection of multiple metastases.

Gadolinium does not reliably enhance low grade gliomas and at the present tissue characterisation is not possible. 